\title{
Value of confucian philosophy and its contemporary value
}

\author{
Hui Yang ${ }^{1, a}$ * \\ ${ }^{1}$ School of ideological and political, Xiamen University of Technology, Fujian, 361024, China \\ aemail: yanghuimm05@163.com
}

Keywords: Values; Confucian philosophy; Constructive postmodernism; Difference

\begin{abstract}
Constructive postmodernism and Chinese traditional confucian values apparently have a consistent philosophy, but this consistency is hidden behind the historical differences between the two types of philosophy. By comparison, two types of axiology has is limited, incommensurability is obvious, it can be said that two types of philosophy on the theory of value is not approximate shape of the gods. By post-modernism and traditional Chinese confucian philosophy values differences clear, we will get double harvest, because it was able to highlight the characteristics of constructive Postmodernism, and it helps to examine the deeper level after constructive modernism in China acceptance and deformation, effectively promote the Chinese traditional culture to achieve a comprehensive innovation.
\end{abstract}

\section{Introduction}

For a long time, people to reflect Chinese traditional culture is the basic point of modernization and modernity, since the mid-20th century, the rise of modernism, for people to re-evaluate Chinese culture provides a new theoretical perspective $[1,2]$. Look at the world has an important influence in the development process of post-modernism, it has thought of "differentiation", "fission" traces in the value orientation and grasp reality, the two have a constructive and deconstructive dimension [3]. Comparison of current academic research for post-modernism and the Chinese traditional philosophy, focused on the comparative study of modernism and the Chinese traditional philosophy after deconstruction, Post for academia in China had a greater impact constructive modernism and traditional Chinese a comparative study of philosophy itself is weak. for constructive Postmodernism and Chinese traditional culture similarities given special attention in the field of values, after projecting a unified presentation Confucian philosophy and constructive values and modernism have in common the fact that the position, and that the two together have a holistic and eco stance, in a particular way concerned with the future of humanity, meaning having ultimate concern, but the lack of constructive post-modernism and Chinese ancient philosophy and especially the ancient Chinese philosophy of body Confucianism values confirm the differences in level of theoretical [4-7].

Our academia seminars on values issues, and the new time of ideological emancipation, reform and opening up and the main social justice modernization construction calendar Cheng closely related. Practice 1978 was carried out by the sole criterion for testing truth to discuss the problem, get rid of the "Quotations standard", "power standards", restored the authority of the practice; get rid of the dogmatism of imprisonment, greatly liberated the people's minds, the CCP Third Plenum of the Party and the state to achieve the focus shifted to open the great historical process of reform and opening up and socialist modernization drive provides an important theoretical basis [8,9]. With my country's economic, social adaptation phase transition, people's thinking has occurred profound changes. People abandoned the interests of the people leaving productivity and abstract talk about the history of the socialist concept of idealism, increasingly concerned about material values, institutional values, cultural values, social values, human values, the value of nature and other issues, and start thinking about the reform and opening up and social Structuring of the modernization drive compatible value system [10].

The problem is that the value of having a major theoretical significance and realistic significance of philosophical problems. Western States in the 20th century, beginning to raise up the value on the research, the Soviet Union, Eastern Europe, Japan and other some countries the Marxist also have to 
explore the establishment of Marxism value Spoken and take was no less outcomes. Reform and opening up to come through in our foreign academic exchanges, the country's external value of research into fruit introduced domestic, but also promote the study and discussion of the value of domestic issues. Liberalism as a fundamental value orientation of western culture, has been in constant development and changing, but classical liberalism to modern liberalism, its core and essence of the concept of freedom is basically the same, and that is based on independent entity of the rights of the individual consciousness. Constructive Postmodernism continues this understanding.

\section{Individualism and holism opposition}

To be sure the overall interests, but does not deny the rights of individuals. For the pursuit of freedom undoubtedly clearly reflects Constructive Postmodernism has the positive side. Although Whitehead importance to relations between the individual and the overall status of the individual and in the whole of. However, he did not eliminate the importance of the individual's own, his attempt to strike a balance between these two poles, repeatedly stressed that he is still the reality of individual, discrete nature of reality and the reality of external relations. And that, in turn, his" eternal objects isolated principle "to ensure the Griffin from the Pan constructive empiricism modernist point of view, that" all individuals (including non-human subject) are real (self-determination) freedom of the individual in a way, and that the different grades individuals with varying degrees of freedom "This will get rid of the anthropocentric, but also get rid of the hegemony in all sectors, recognition of all life (or life) of individual equality. in addition, the post-modernist hope to establish a constructive human their equal relationship, against male chauvinism and power politics, that the modern spirit is said to be a one-sided male spirit of modern critique, including the denial of the feminist movement and the care of the patriarchy that women as the main representative of women, bear a creative role, an important role in the complex interactions of unity and diversity. Meaning and function of value and value was shown in Figure 1.

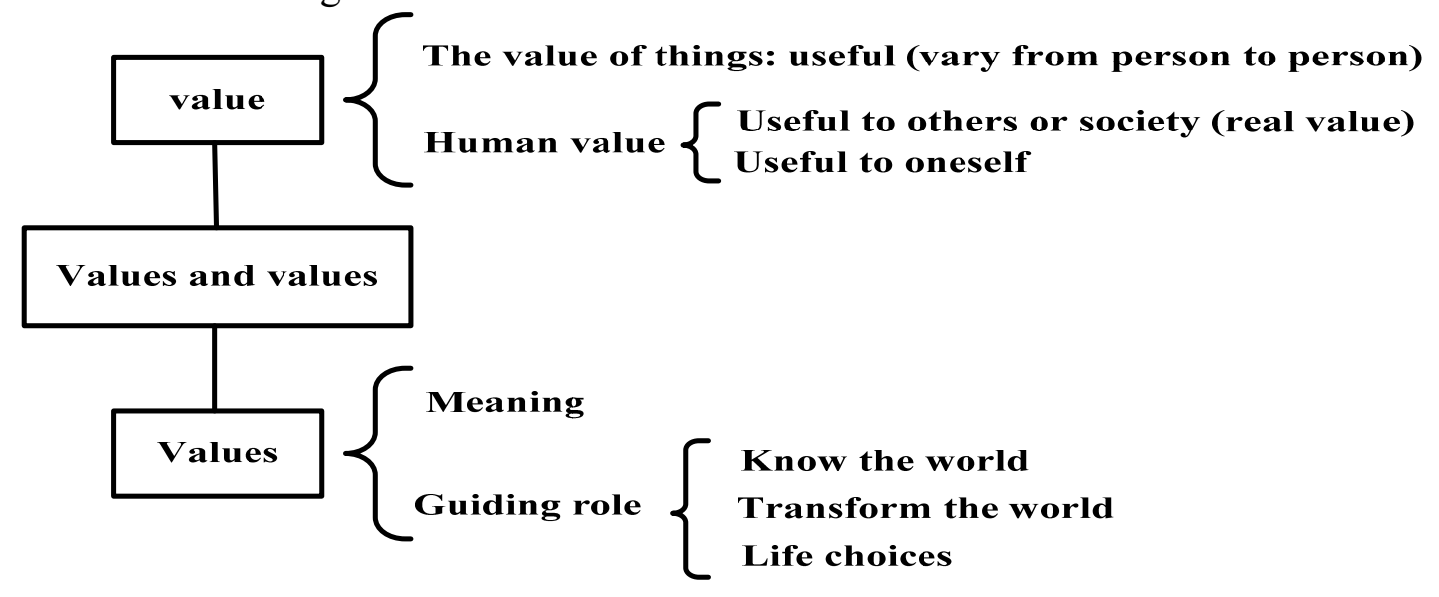

Figure 1. Meaning and function of value and value

Confucian culture is lacking is precisely the spirit of liberalism and individual-based acknowledgment, it emphasizes the holistic and order. Under the influence of traditional holism, etc., as well as the whole confucian culture including traditional Chinese culture, including Taoism has been unable to form a strict sense of awareness of their rights, and also failed to contribute close to the concept of the meaning of freedom. At the same time, the essence of the spirit of Chinese culture is an emphasis on group of holism, and thus is a specific naturalism. Their main orientation is not to go beyond the natural relationship, not beyond the realm of rationality into the VIP customs, habits, experience, common sense and other free cultural level, not people gradually get rid of the shackles of patriarchal constraints and other natural kinship relations, but stressed return to nature and affirmation, Reiji order to achieve a society of individuals well-organized and determined clever, but it is a pity that the organization and the individual is determined not to let them maximize the potential 
of life, not to make individual self responsible for realization of the process of life. Instead confused individual immobilization of seniority, under "Jun Chen Gang, the father of the child, husband wife Gang" and "three bonds" Bound, in which the body and it could not move, there is no way out personality, some individuals ignored the most basic, inalienable rights of individuals as an integral part of the overall attached and unconditional obedience whole, and patriarchal, as blood ties, culture groups, personality, personality constraint. Meanwhile, the traditional holism exploited by the ruling class, and contributed to the royal husband supremacy.

\section{Differences in understanding of the fact that the value of unity}

Constructive Postmodernism is a scientific, ethical, aesthetic and religious intuitions of the new system. It is not against science itself, is opposed to the kind of modern natural science alone allow the participation of scientific data, requires a comprehensive fact and value, science and religion, between man and nature objective and subjective, human and social structure our worldview scientism. Griffin believes, scientific, spiritual and social life conditions for the existence of each other, the relationship between these three are interdependent relationship. Because the human spirit can be partially beyond imagination and feel the conditions specified in, and thus "a post-modern science and spirit is still in a fairly modern social order to be able to get considerable development. Confucianism China does not attach importance to the fact that natural physical aspects of awareness and lack of a unified philosophy and scientific spirit will own independent scientific universe of rational thinking, but can not form a set It covered the body of scientific knowledge or metaphysics school. Philosophical meaning and basic problems was shown in Figure 2.

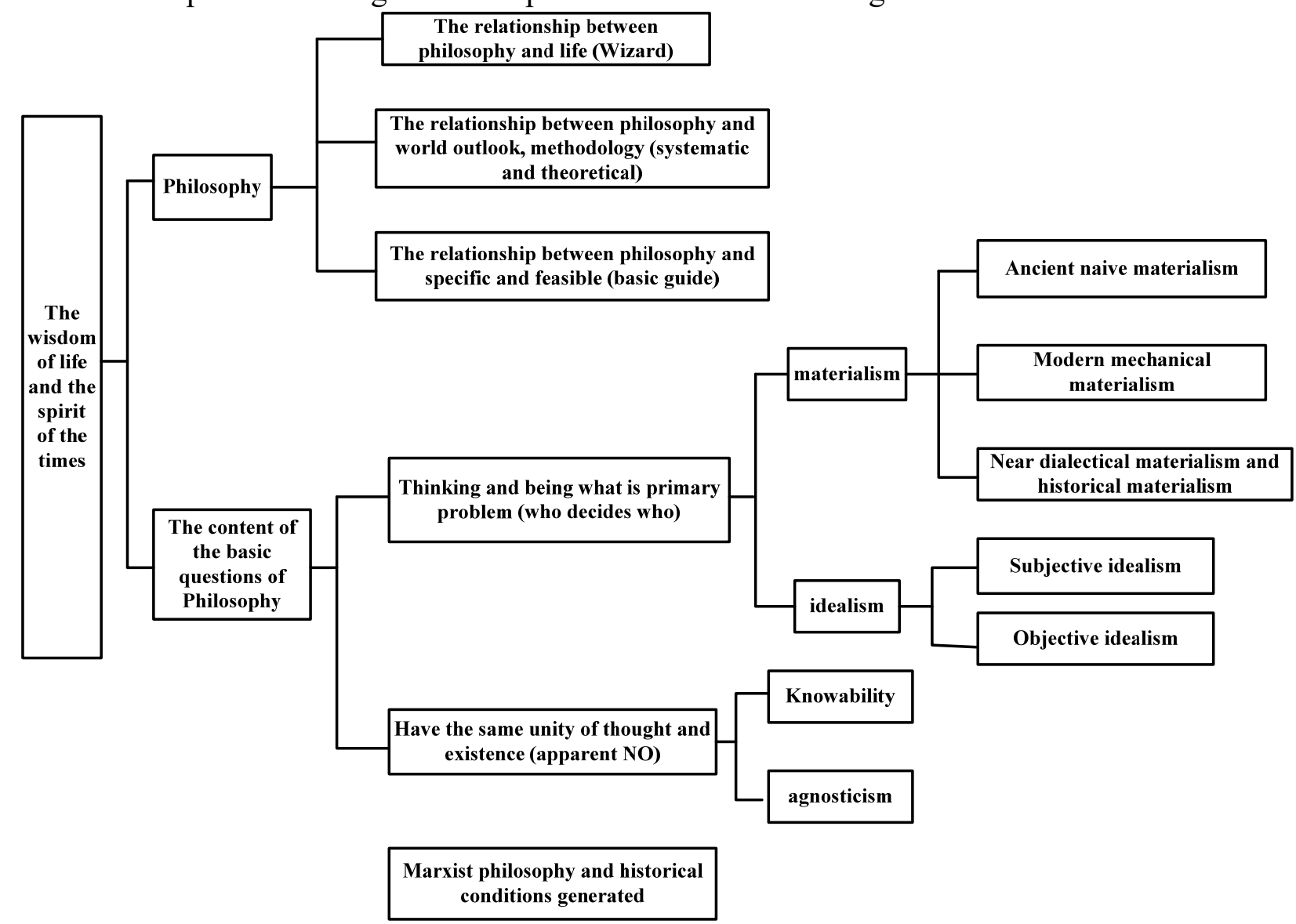

Philosophical Meaning and Basic Problems

Figure 2. Philosophical meaning and basic problems 
On Constructive Postmodernism, first, objective things for people who have the same understanding of the meaning, can be used as the object of knowledge. Whitehead, for all practical object was once a subject, all subjects will become the object. Original experience of people, animals, plants and stones present in the common reality of all beings have a universal unconscious subjectivity. Secondly, Constructive modern philosophy Factual approach to understanding highly integrated. Constructive Postmodernism ontological intuition and experience both logical argument, not only pay attention to common sense approach, but also pay attention to logical reasoning, both emphasize analysis, more emphasis on integrated, both respected speculative intuition, but also focus on scientific induction, integrated use of various methods. Whitehead believes that all sensory perceptions are only the result of our body functions, each sensory perception obtained, expose the nature of the universe in terms of a very superficial, thus generating process exists for any real grasp of all physical and grasp the concept, the main objective of the Adaptation and value selection comprehensive results, saying that "the real discovery method as aircraft in flight. it is in the earth observation constituted by individual takeoff, then imaginative generalization constituted by a thin fly in the atmosphere, in order to obtain the final was a reasonable explanation becomes sensitive to new observation landing. Maslow's hierarchy of needs was shown in Figure 3.

Maslow's hierarchy of needs

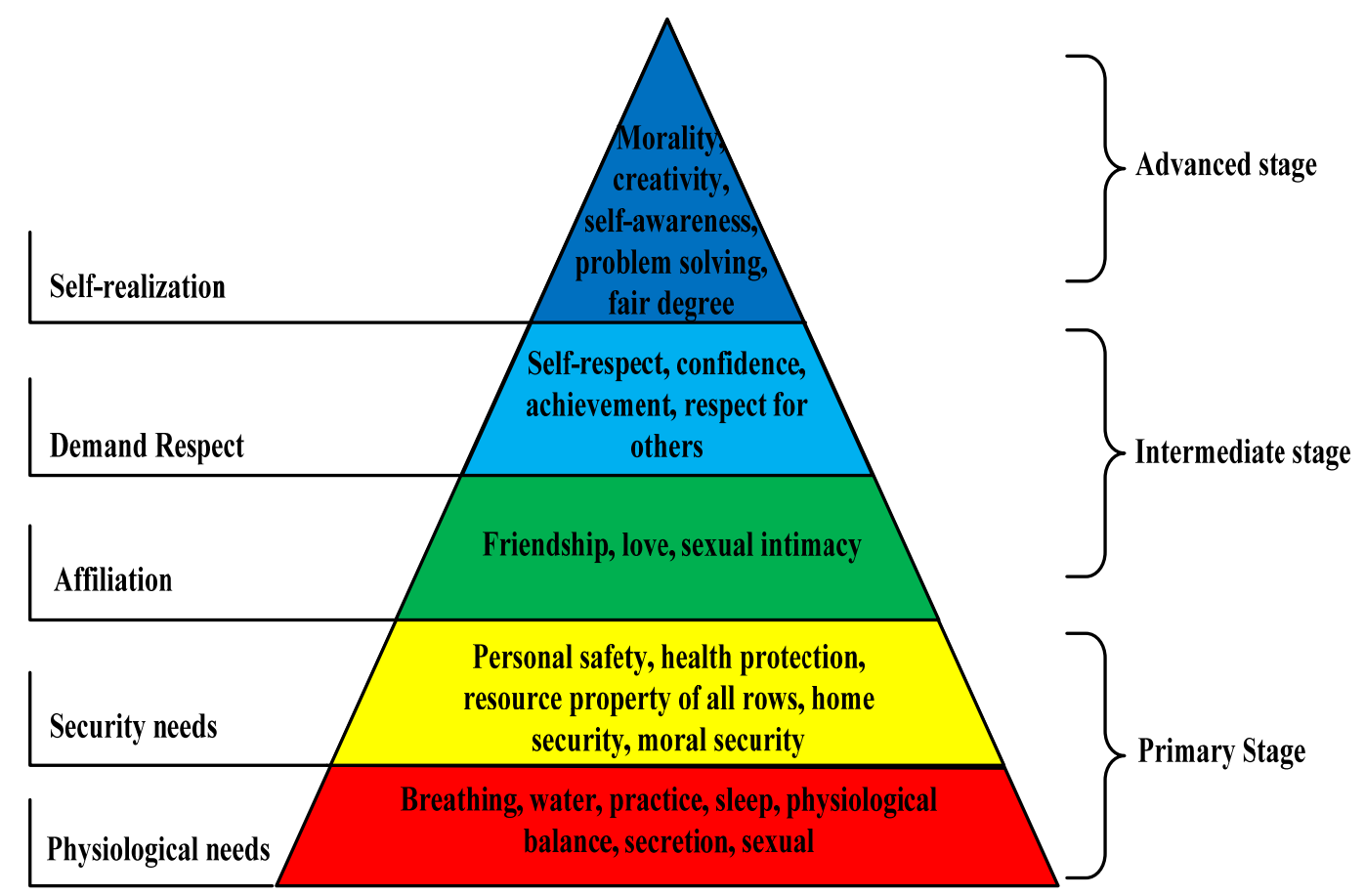

Figure 3. Maslow's hierarchy of needs

Constructive Postmodernism and Chinese traditional Confucian philosophy values show the difference can be further defining characteristic of postmodernism constructive. Schematic terms, it is considered Constructive Postmodernism does not get rid of the traditional problems of Western philosophy, and narrative category system, such as a body and to explore the phenomenon of mind and matter, and a more static and dynamic presence and generate, mono- and dual, determinism and free will, and mechanistic teleology, therefore, fundamentally speaking, constructive Postmodernism is still one of the schools of Western philosophy, and its similarity to a representation of oriental culture its spirit and scope of the system were saturated with the spirit of the West. They are based on Western academic point of mediation conducted this East-West fusion of the two values, this may not reconcile thorough and in-depth. Because for them, they understand the Chinese traditional philosophy is quite limited, there is a period of Whitehead and even taking a fierce critic of Confucius attitude. 


\section{Conclusions}

Constructive Postmodernism and Chinese traditional Confucian philosophy values due to the different economic base and other reasons, the two are essentially different contents, methods are different, the macro processes the Vision philosophy and ancient Chinese Confucian philosophy of values contrasting conclusion that the two types of philosophy in philosophy is the shape and form of God does not approximate, broadly similar in terms of two types of philosophy can not exactly explain the real situation contrasts two types of philosophy, but the formation of a constructive post-modernism and the ancient Chinese Confucian philosophy and limitations characteristic double shielding, after recognition of traditional Chinese culture is not conducive to a comprehensive realization of innovative and constructive modernist characteristics.

\section{References}

[1] Juan Z. On Translating Chinese Internet Buzzwords into English from the Perspective of Skopos Theory: Taking the Example of 2012 Chinese Internet Buzzwords[J]. Journal of Hubei Engineering University, 2013, 2: 017.

[2] Chen H. Research on Literary Translation Capability and the Construction of Training Mode[C]//2015 International Conference on Education Technology and Economic Management. Atlantis Press, 2015.

[3] Ajayi L. High school teachers' perspectives on the English language arts Common Core State Standards: an exploratory study[J]. Educational Research for Policy and Practice, 2016, 15(1): $1-25$.

[4] Zhang Z. Chinese and Canadian teachers implement a hybrid Sino-Canadian curriculum: A multiliteracies perspective[J]. Teaching and Teacher Education, 2015, 48: 106-116.

[5] Underwood P R. Teacher beliefs and intentions regarding the instruction of English grammar under national curriculum reforms: A Theory of Planned Behaviour perspective[J]. Teaching and Teacher education, 2012, 28(6): 911-925.

[6] ZHOU Y, WANG Y. Theoretical basis and strategy selections for the English translation of traditional Chinese medical terms from 1981 to 2010[J]. China Journal of Traditional Chinese Medicine and Pharmacy, 2013, 4: 042.

[7] Al-Issa A S M. Making a Case for New Directions in English Language Teaching Research at an Omani University: A Critical Qualitative Content Analysis Report[J]. The Qualitative Report, 2015, 20(5): 560 .

[8] Liu D, Li L. Analysis of the science development of the PST-CCE in applied undergraduate colleges and universities [J]. 2015.

[9] Celik S. Internet-assisted technologies for English language teaching in Turkish universities[J]. Computer Assisted Language Learning, 2013, 26(5): 468-483.

[10]Zhong Q, Xu Y, Yu X H, et al. Study of the virtual campus ramble for the android mobile phone[C]//Advanced Materials Research. 2013, 718: 2252-2258. 